\title{
Ungewöhnliche vordere Kapselfibrose bei „Rhexis-Occlusio“
}
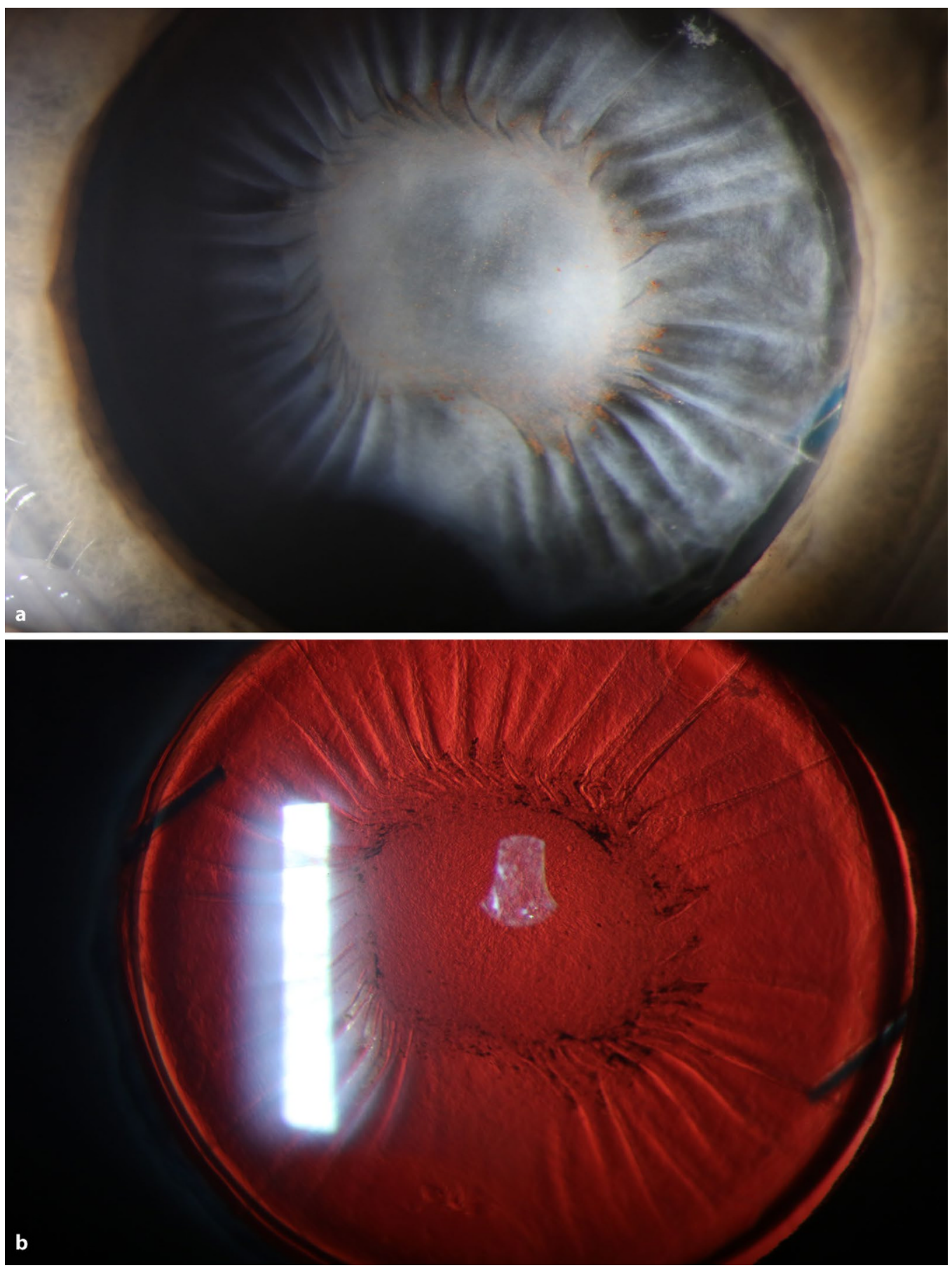

Abb. 1a, b $\Delta$ Aspekt der vorderen Linsenkapsel bei erweiterter Pupille 10 Monate nach Phakoemulsifikation mit Hinterkammerlinsenimplantation im seitlichen und regredienten Licht. Zustand nach mehrfacher Operation einer Netzhautablösung mit Vitrektomie und Silikonölinstillation. Die Kunstlinse liegt gut zentriert im Kapselsack. Die vordere Kapsulorhexis-Öffnung ist wahrscheinlich durch organisiertes Fibrin und nicht durch eine (prinzipiell mögliche) fibröse Proliferation vom Rhexis-Rand aus verschlossen. Bei einem Visus von 0,05 erfolgte keine operative Revision der "RhexisOcclusio", die eine histologische Differenzierung erlaubt hätte. Sehr ungewöhnlich sind die entstandenen, erstaunlich gleichmäßigen, radiären (Fibrose-) Leisten im Bereich der fibrosierten, vorderen Linsenkapsel

\section{Martin Rohrbach,} Spyridon Dimopoulos

Universitäts-Augenklinik, Tübingen, Deutschland

\section{Korrespondenzadresse:}

Prof. Dr. Jens Martin Rohrbach Universitäts-Augenklinik Elfriede-Aulhorn-Str. 7 72076 Tübingen, Deutschland Martin.Rohrbach@ med.uni-tuebingen.de

Ophthalmologe $2021 \cdot 118: 533$

https://doi.org/10.1007/s00347-02101416-2

(c) Springer Medizin Verlag $\mathrm{GmbH}$, ein Teil von Springer Nature 2021 